\title{
Dispersal capacity of Haematopota spp. and Stomoxys calcitrans using a mark-release-recapture approach in Belgium
}

\author{
L. LEMPERE UR ${ }^{1}$, C. SOHIER ${ }^{2}$, F. S MEET S ${ }^{3}$, F. MARÉ CHA L ${ }^{1}$, \\ D. B ER K V E N S ${ }^{2}$, M. M A D D R R , F. F R A N I S ${ }^{3}$ and B. L O S O N ${ }^{1}$ \\ ${ }^{1}$ Laboratory of Parasitology and Parasitic Diseases, Centre for Fundamental and Applied Research for Animal Health (FARAH), \\ Faculty of Veterinary Medicine, University of Liège, Liège, Belgium, ${ }^{2}$ Department of Biomedical Sciences, Institute of Tropical \\ Medicine, Antwerp, Belgium, ${ }^{3}$ Gembloux Agro-Bio Tech, Functional and Evolutionary Entomology Unit, University of Liège, \\ Gembloux, Belgium and ${ }^{4}$ Department of Veterinary Tropical Diseases, University of Pretoria, Pretoria, South Africa
}

\begin{abstract}
The dispersion potential of mechanical vectors is an important factor in the dissemination of pathogens. A mark-release-recapture experiment was implemented using two groups (unfed and partially fed) of the Tabanidae (Diptera) (Haematopota spp.) and biting Muscidae (Diptera) (Stomoxys calcitrans) most frequently collected in Belgium in order to evaluate their dispersion potential. In total, 2104 specimens of Haematopota spp. were collected directly from horses and 5396 S. calcitrans were collected in a cattle farm using hand-nets. Some of these insects were partially fed in vitro and all were subsequently coloured. Overall, 67 specimens of S. calcitrans $(1.2 \%)$ and 17 of Haematopota spp. (0.8\%) were recaptured directly on horses. Stomoxys calcitrans flew maximum distances of $150 \mathrm{~m}$ and $300 \mathrm{~m}$ when partially fed and unfed, respectively. Haematopota spp. travelled maximum distances of $100 \mathrm{~m}$ and $200 \mathrm{~m}$ when partially fed and unfed, respectively. Segregation measures seem essential in order to reduce the risk for pathogen transmission. A distance of $150 \mathrm{~m}$ appears to be the minimum required for segregation to avoid the risk for mechanical transmission, but in areas of higher vector density, this should probably be increased.
\end{abstract}

Key words. Haematopota spp., Stomoxys calcitrans, in vitro feeding, mark-release-recapture, Belgium.

\section{Introduction}

Mechanical transmission by arthropods is generally accepted as a major route for the dissemination of equine infectious anaemia virus (EIAV) (Mullen \& Durden, 2009) and other pathogens such as Trypanosoma evansi, which was introduced recently into France and Spain (Gutierrez et al., 2010), Anaplasma marginale (Mullen \& Durden, 2009) and Besnoitia besnoiti, which is responsible for besnoitiosis in cattle, an emergent disease in France, Spain and Portugal (Cortes et al., 2006; Fernandez-Garcia et al., 2010; Liénard et al., 2011).
Equine infectious anaemia (EIA) is a notifiable disease with a potentially worldwide distribution. This virus causes persistent infection in horses, which represent its major source of transmission. Several outbreaks of EIA were recently reported in various Belgian provinces (Caij \& Tignon, 2014). Some infections occurred after the import of infected horses, demonstrating local transmission events. At present, no treatment is available and control measures are limited to the culling of horses found to be infected, and to segregation or restrictions of movement. These recent outbreaks have dramatically increased local veterinary officers' concern about EIA and its transmission.

Correspondence: Laetitia Lempereur, Laboratory of Parasitology and Parasitic Diseases, Centre for Fundamental and Applied Research for Animal Health (FARAH), Faculty of Veterinary Medicine, University of Liège, Quartier Vallée 2, Avenue de Cureghem 6 B43a, 4000 Liège, Belgium. Tel.: +32 4366 4093; Fax: +32 4366 4097; E-mail: llempereur@ulg.ac.be 

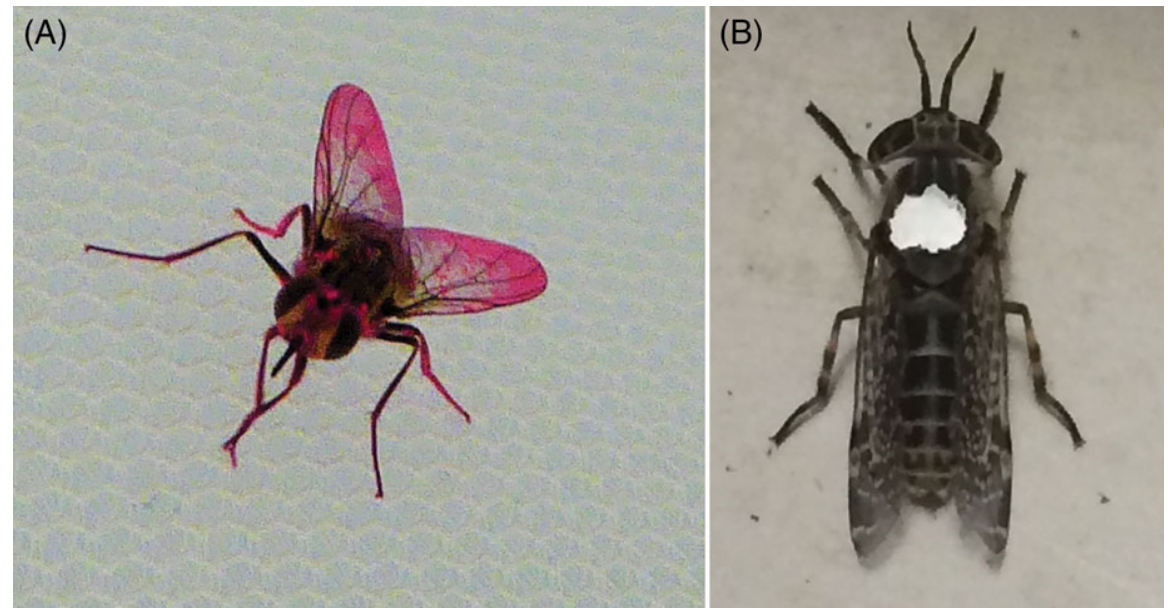

Fig. 1. (A) Stomoxys calcitrans coloured using fluorescent powder dyes blown on to the insect. (B) Haematopota spp. coloured on the thorax using a coloured marking pen. [Colour figure can be viewed at wileyonlinelibrary.com].

Large haematophagous insects, especially horse flies (Diptera: Tabanidae), appear to be the most efficient vectors. However, stable flies (Diptera: Muscidae) were also reported to be capable of mechanical transmission of EIAV (Hawkins et al., 1973; Foil, 1989; Mullen \& Durden, 2009; Baldacchino et al., 2013).

Numerous factors can influence the dispersal of these vectors and the spread of pathogens, depending on the vertebrate host (Horvath et al., 2010), vector (Baldacchino et al., 2014), pathogen and environment (Herczeg et al., 2015).

The feeding behaviours of a given group of vectors are of particular interest as they may represent a major key to understanding the potential spread of an infectious agent. The behaviours of Tabanidae and Muscidae are not identical, which may influence transmission efficiency. Previous studies demonstrated that the interval between bloodmeals is quite long in tabanids (5-7 days), which limits transmission potential as most pathogens have a short survival period on the mouthparts (Foil $\&$ Hogsette, 1994). However, the bites of these tabanids are very painful and this limited transmission potential may be modified by vertebrate host defensive behaviour that interrupts vector feeding (Foil \& Issel, 1991). Consequently, tabanids will increase their number of short feeding periods and will thus participate more actively in pathogen dissemination. By contrast, Stomoxys flies (Diptera: Muscidae) are frequent feeders in which the interval between bloodmeals varies from $4 \mathrm{~h}$ to $72 \mathrm{~h}$ (Baldacchino et al., 2013). Moreover, stable flies can regurgitate part of a previous bloodmeal before taking another one and thereby easily transmit the high doses of pathogen required for the transfer of an agent of infection (Butler et al., 1977).

The environment also plays a major role by determining vector density and risk for rapid spread. Rainfall, temperature and sunshine are factors with major influence on vector density (Herczeg et al., 2015). Tabanid immature stages (eggs, larvae and nymphs) are mainly found in humid environments (river banks, water bodies, marshy areas), whereas S. calcitrans is a ubiquitous cosmopolitan species.

Very few studies on the dispersal potential of these insect vectors have been performed in the European context.
Consequently, lack of knowledge about the potential vector transmission of EIA in Belgium reduces the ability to implement adapted control measures and to improve control schemes.

In this context, a mark-release-recapture experiment was implemented using two groups (unfed and partially fed) of the tabanids (Haematopota spp.) and biting muscids (S. calcitrans) most frequently collected in Belgium.

\section{Materials and methods}

Tabanidae were collected outdoors directly from horses in a horse-riding establishment in Belgium (Grand-Leez), using small plastic vials. Muscidae were collected using hand-nets in a cattle farm (Gembloux) during the summer in 2015. These insects were subsequently identified using morphological keys (Chlava et al., 1972; Zumpt, 1973). In total, 2104 Haematopota spp. and 5396 S. calcitrans were collected. Haematopota spp. and S. calcitrans were selected for the experiment as these represent the species most frequently collected in the region. The insects were placed in rearing cages in batches of 150 S. calcitrans and 50 Haematopota spp. for an average of 2-3 days before their release depending on meteorological conditions. They were fed a sugar-water solution (10\% saccharose) deposited on Whatman ${ }^{\circledR}$ paper placed in each cage. Rearing conditions (temperature, relative humidity) were optimized to guarantee an optimal survival rate. A proportion of the insect collections were not fed blood prior to their release. The others were partially fed on heparinized cattle blood in vitro prior to release using a Hemotek ${ }^{\circledR}$ artificial membrane feeding system (Hemotek Ltd, Blackburn, U.K.). This technique was implemented on an artificial silicone membrane placed on a feeder linked to an electric system that maintained the blood at a controlled temperature. In this case, the temperature was set at $34^{\circ} \mathrm{C}$. A membrane provided by Hemotek Ltd was used on the feeder and its thickness was adjusted to Tabanidae and Muscidae feeding. Tabanidae and Muscidae have long and strong 


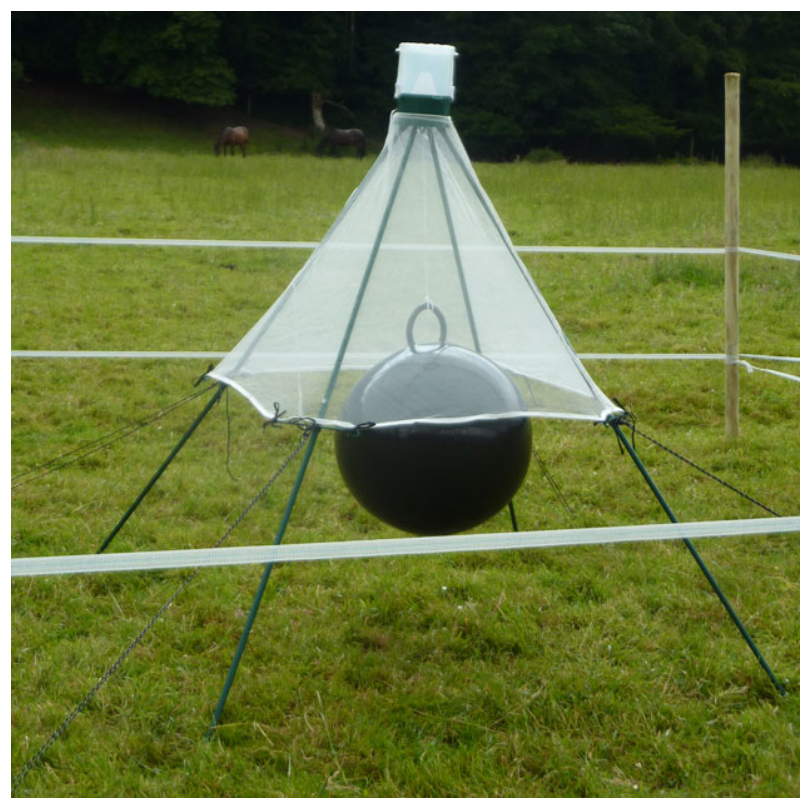

Fig. 2. H-trap used for tabanids and Stomoxys calcitrans recapture. [Colour figure can be viewed at wileyonlinelibrary.com].

mouthparts compared with other biting insects (midges), which required the thickness of the membrane to be doubled. Partial feeding was achieved by placing feeders on cages for a maximum of $20 \mathrm{~min}$ and moving them every $30 \mathrm{~s}$ in the case of S. calcitrans and every minute in the case of Haematopota spp. Subsequently, partially fed insects were placed in another rearing cage to avoid their completion of a full bloodmeal.

Stomoxys calcitrans were coloured using fluorescent powder dyes (Swada; Dane Color UK Ltd, Stalybridge, U.K.), which were blown on to the insects directly in the experimental field in order to reduce potential mortality (Fig. 1). This technique was not applied to Haematopota spp. as it was shown to restrain their flight aptitude in preliminary trials. Therefore, an alternative marking method that had no effect on survival and subsequent flight was applied. Haematopota spp. were coloured individually on the thorax using colour marking pens (Uni Posca; Mitsubishi Pencil Co. Ltd, Tokyo, Japan) commonly used for queen bee marking (Fig. 1).

These unfed and partially fed coloured insects were released at progressive distances from two bait horses surrounded by H-traps (Fig. 2) baited by an octenol slow-release device (Fig. 3). An interval of 30 min was applied consistently between artificial feeding and release. Recaptures were made directly on horses and in surrounding $\mathrm{H}$-traps for $3 \mathrm{~h}$ after release. The attractiveness of the two horses had been previously evaluated by direct collection from these horses. Releases started at a distance of $25 \mathrm{~m}$ for $S$. calcitrans and $50 \mathrm{~m}$ for Haematopota spp. Each specific distance was associated with insects of a specific colour. As soon as the viability of a specific distance had been validated by the recapture of at least one insect, the test distance was increased by $25 \mathrm{~m}$ or $50 \mathrm{~m}$. The release procedure at the greatest distance used was repeated two or three times to ensure that no insect was recaptured.

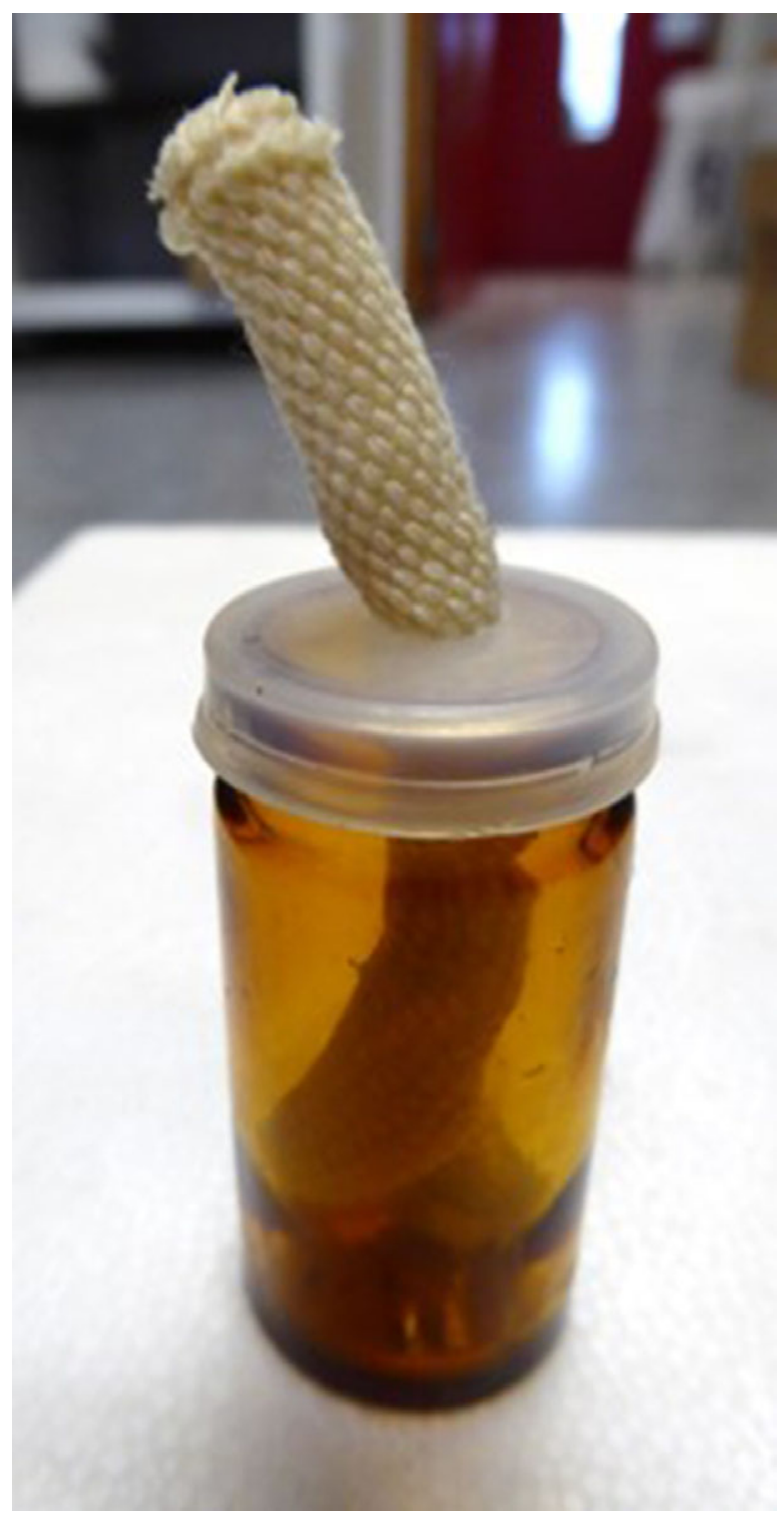

Fig. 3. Octenol slow-release device placed at the basis of $\mathrm{H}$-traps during the recapture. [Colour figure can be viewed at wileyonlinelibrary.com].

The release area consisted of open land (meadows and crops) in Grand Leez (Belgium), without other animals in the vicinity. Environmental conditions were recorded using a thermohygro chip and cup anemometer (Model WS-3900, Alecto, 's-Hertogenbosch, The Netherlands). Releases and recaptures were performed early in the afternoon when the temperature had reached its maximum and environmental conditions were suitable (dry with a maximum wind speed of $15 \mathrm{~km} / \mathrm{h}$ ). Insects were released against the direction of the wind.

Statistical analysis was performed in Stata/MP Version 14.2 (StataCorp LP, College Station, TX, U.S.A.). Logistic regression was applied to the data in order to model and, where possible, extrapolate the results. A Firth penalized maximum likelihood method for rare events was used (Heinze \& Schemper, 2002). 
Table 1. Results of Stomoxys calcitrans release-recapture experiments.

\begin{tabular}{llllll}
\hline & \multicolumn{3}{l}{ S. calcitrans specimens, $n$} & \\
\cline { 2 - 4 } $\begin{array}{lllll}\text { Distance, } \\
\mathrm{m}\end{array}$ & $\begin{array}{l}\text { Part-fed } \\
\text { released }\end{array}$ & $\begin{array}{l}\text { Unfed } \\
\text { released }\end{array}$ & $\begin{array}{l}\text { Part-fed } \\
\text { recaptured }\end{array}$ & $\begin{array}{l}\text { Unfed } \\
\text { recaptured }\end{array}$ & $\begin{array}{l}\text { Date of } \\
\text { experiment }\end{array}$ \\
\hline 25 & 150 & 150 & 7 & 8 & $11 / 06 / 2015$ \\
50 & 150 & 150 & 5 & 3 & $11 / 06 / 2015$ \\
100 & 150 & 150 & 1 & 0 & $11 / 06 / 2015$ \\
100 & 83 & 145 & 6 & 2 & $26 / 06 / 2015$ \\
125 & 147 & 125 & 0 & 3 & $26 / 06 / 2015$ \\
150 & 105 & 57 & 0 & 0 & $26 / 06 / 2015$ \\
150 & 150 & 150 & 4 & 12 & $08 / 07 / 2015$ \\
200 & 150 & 150 & 0 & 12 & $08 / 07 / 2015$ \\
250 & 150 & 200 & 0 & 2 & $08 / 07 / 2015$ \\
250 & 300 & 300 & 0 & 1 & $26 / 08 / 2015$ \\
300 & 130 & 134 & 0 & 1 & $03 / 08 / 2015$ \\
300 & 450 & 510 & 0 & 0 & $13 / 08 / 2015$ \\
300 & 150 & 170 & 0 & 0 & $26 / 08 / 2015$ \\
350 & 140 & 0 & 0 & 0 & $03 / 08 / 2015$ \\
350 & 150 & 150 & 0 & 0 & $07 / 08 / 2015$ \\
400 & 150 & 150 & 0 & 0 & $26 / 08 / 2015$ \\
& 2705 & 2691 & 23 & 44 & \\
\hline
\end{tabular}

Table 2. Results of Haematopota spp. release-recapture experiments.

\begin{tabular}{llllll}
\hline & \multicolumn{3}{l}{ Haematopota spp. specimens, $n$} & \\
\cline { 2 - 4 } $\begin{array}{lllll}\text { Distance, } \\
\mathrm{m}\end{array}$ & $\begin{array}{l}\text { Part-fed } \\
\text { released }\end{array}$ & $\begin{array}{l}\text { Unfed } \\
\text { released }\end{array}$ & $\begin{array}{l}\text { Part-fed } \\
\text { recaptured }\end{array}$ & $\begin{array}{l}\text { Unfed } \\
\text { recaptured }\end{array}$ & $\begin{array}{l}\text { Date of } \\
\text { experiment }\end{array}$ \\
\hline 50 & 150 & 150 & 0 & 0 & $26 / 06 / 2015$ \\
50 & 50 & 162 & 2 & 9 & $08 / 07 / 2015$ \\
75 & 0 & 37 & 0 & 1 & $08 / 07 / 2015$ \\
100 & 100 & 100 & 0 & 0 & $11 / 06 / 2015$ \\
100 & 150 & 150 & 1 & 0 & $26 / 06 / 2015$ \\
100 & 150 & 150 & 0 & 0 & $26 / 06 / 2015$ \\
100 & 50 & 50 & 0 & 0 & $08 / 07 / 2015$ \\
100 & 0 & 55 & 0 & 0 & $08 / 07 / 2015$ \\
100 & 50 & 50 & 2 & 0 & $03 / 08 / 2015$ \\
150 & 50 & 50 & 0 & 1 & $03 / 08 / 2015$ \\
200 & 50 & 150 & 0 & 1 & $03 / 08 / 2015$ \\
200 & 50 & 50 & 0 & 0 & $07 / 08 / 2015$ \\
250 & 50 & 50 & 0 & 0 & $03 / 08 / 2015$ \\
& 900 & 1204 & 5 & 12 & \\
\hline
\end{tabular}

\section{Results}

Totals of 2705 partially fed and 2691 unfed S. calcitrans distributed in 16 batches, respectively, and 900 partially fed and 1204 unfed Haematopota spp. distributed in 13 batches, respectively, were released (Tables 1 and 2).

Stomoxys calcitrans were released at distances of $25-400 \mathrm{~m}$ and Haematopota spp. at distances of 50-250 m.

In total, 67 specimens of $S$. calcitrans and 17 of Haematopota spp. were recaptured directly on horses, giving recapture rates of $0-5 \%$. No marked insects were collected in surrounding H-traps.

Stomoxys calcitrans flew over maximum distances of $150 \mathrm{~m}$ and $300 \mathrm{~m}$ when partially fed and unfed, respectively, whereas
Table 3. Probability of recapture of Stomoxys calcitrans and Haematopota spp. according to distance of release.

\begin{tabular}{|c|c|c|c|}
\hline \multirow[b]{2}{*}{$\begin{array}{l}\text { Distance, } \\
\mathrm{m}\end{array}$} & \multicolumn{3}{|l|}{ Probability } \\
\hline & $\begin{array}{l}\text { Unfed } \\
\text { S. calcitrans }\end{array}$ & $\begin{array}{l}\text { Fed } \\
\text { S. calcitrans }\end{array}$ & $\begin{array}{l}\text { Unfed } \\
\text { Haematopota } \\
\text { spp. }\end{array}$ \\
\hline 25 & 0.0519 & 0.0588 & - \\
\hline 50 & 0.0435 & 0.0393 & 0.0219 \\
\hline 75 & - & - & 0.0142 \\
\hline 100 & 0.0303 & 0.0173 & 0.0091 \\
\hline 125 & 0.0253 & 0.0114 & - \\
\hline 150 & 0.0211 & 0.0075 & 0.0038 \\
\hline 200 & 0.0146 & 0.0032 & 0.0016 \\
\hline 250 & 0.0101 & 0.0014 & 0.0006 \\
\hline 300 & 0.0070 & 0.0006 & - \\
\hline 350 & 0.0048 & 0.0003 & - \\
\hline 400 & 0.0033 & 0.0001 & - \\
\hline
\end{tabular}

Haematopota spp. travelled distances of $100 \mathrm{~m}$ and $200 \mathrm{~m}$ when partially fed and unfed, respectively (Tables 1 and 2).

The model based on the logistic regression indicated that, in S. calcitrans, there is a probability of recapture of 0.007 in an unfed fly at $300 \mathrm{~m}$ and in a partially fed fly at $150 \mathrm{~m}$. The probability of recapture in unfed Haematopota spp. at $200 \mathrm{~m}$ is $<0.002$. Data available for partially fed Haematopota spp. generated a non-significant result, probably because the number of partially fed Haematopota spp. released was relatively limited (Table 3).

\section{Discussion}

Tabanids and biting flies represent the main mechanical vectors of different pathogens. In principle, bigger flies such as tabanids are more efficient vectors because their bites are painful consequently their bloodmeals are often interrupted by the defensive behaviour of the host and are then repeated. The mouthparts of these big flies can retain relatively large amounts of fresh and potentially infected blood (1-12 nL) (Foil et al., 1987; Scoles et al., 2008). By contrast, the volume of blood that can be retained in smaller vectors, such as $S$. calcitrans, is much lower (around $0.03 \mathrm{~nL}$ ) (Scoles et al., 2005). This residual blood may be partially inoculated into another animal during the early stage of the next attempt to bite. The success of transmission will also depend on the pathogenaemia of the host and the persistence of the agent on the vector's mouthparts. In the case of EIAV, the virus titre fluctuates from day to day and is highest during the acute phase (Issel \& Foil, 2015). Hawkins et al. (1976) demonstrated that EIAV at $10^{6}$ infectious doses $/ \mathrm{mL}$ from a febrile donor was transmitted by a single horse fly (Tabanus fuscicostatus). However, it is known that during mechanical transmission, the survival rate of the parasite decreases and the parasite will be absent from the vector within a short period. In general, transmission is successful when the next bite is performed within 30 min to $1 \mathrm{~h}$ (Hawkins et al., 1976; Williams et al., 1981).

The very painful bite inflicted by tabanids is probably a key factor in this respect. However, most of the time $S$. calcitrans is 
much more abundant than horse flies, which may compensate for its lower capacity to retain fresh blood and thereby increase the relevance of its vectorial capacity. In other words, a high number of small flies may be as efficient as a low number of large flies (Desquesnes et al., 2013). Therefore, vector density may be particularly important in the evaluation of transmission potential.

An alternative to immediate mechanical transmission occurs when blood from the insect's gut or crop is regurgitated (Butler et al., 1977). Because pathogens can survive longer within the vector, this may facilitate delayed transmission (Baldacchino et al., 2013). This observation may have important epidemiological implications and should be confirmed.

The aim of this study was to evaluate the dispersion potential of unfed and partially fed Haematopota spp. and S. calcitrans in the Belgian context. These experiments demonstrated that dispersion potential is influenced by the stage of repletion: unfed vectors flew longer distances than partially fed flies. This finding is in agreement with those of other surveys (Chippaux et al., 2000; Barros \& Foil, 2007; Taylor et al., 2010) and with the supposition that the unfed vector requires a bloodmeal more urgently and therefore will fly a longer distance to find a host. In this study, partially fed Haematopota spp. and S. calcitrans were able to fly maximum distances of $100 \mathrm{~m}$ and $150 \mathrm{~m}$, respectively, in the absence of host competition in the vicinity. Although this study did not take into account the influence of the presence of other horses in the vicinity, Foil (1983) and Barros $\&$ Foil (2007) showed that $100 \%$ of flies that re-fed on a horse following a naturally or artificially interrupted feeding returned to the original host when no other horses were present within a radius of $50 \mathrm{~m}$. Therefore, pathogen transmission will occur more frequently within a herd than between distinct herds and, consequently, the application of prevention measures such as the segregation of infected and susceptible horses should reduce the potential risk for pathogen transmission. However, further research into the diversity of potential vector species, as well as vector behaviour, is required to confirm this.

The experimental model developed from these field data showed that increasing the number of flies released enhances the probability of capturing flies at greater distances. Therefore, higher vector density will increase the potential risk for transmission and will probably also extend the distance at which such risk applies.

Further research should be designed with the aim of developing models for the dispersion potential of vectors with reference to vector density at the local level, the influence of hosts in the vicinity and the effects of increasing the number of partially fed vectors released on their dispersion behaviour.

\section{Acknowledgements}

The authors extend their gratitude to the horse-riding establishment Manège du Try-Lambord and to Centre Wallon de Recherches Agronomiques for allowing the present experiments to be conducted on their properties. The authors also thank Ludovic Martinelle (University of Liege, Care FEPEX), Irene Tosi (University of Liege, Equine Clinical Department),
Ivo Vangerven, Laurent Leinartz (University of Liege), Franciscus Jacobs (University of Ghent) and Marc Coosemans, (Institute of Tropical Medicine, Medical Entomology Unit), for their help and advice during this project. This study was achieved with the financial support of the Public Health and Agriculture Services of the Belgian government (project Eqiavec 1 RT 14/6). The work carried out by LL and BL was conducted under the framework of EurNegVec COST Action TD1303EurNegVec.

The authors declare no conflicts of interest.

\section{References}

Baldacchino, F., Muenworn, V., Desquesnes, M., Desoli, F., Charoenviriyaphap, T. \& Duvallet, G. (2013) Transmission of pathogens by Stomoxys flies (Diptera, Muscidae): a review. Parasite (Paris, France), 20, 26.

Baldacchino, F., Gardès, L., de Stordeur, E., Jay-Robert, P. \& Garros, C. (2014) Blood-feeding patterns of horse flies in the French Pyrenees. Veterinary Parasitology, 199, 283-288.

Barros, A.T.M. \& Foil, L.D. (2007) The influence of distance on movement of tabanids (Diptera: Tabanidae) between horses. Veterinary Parasitology, 144, 380-384.

Butler, J.F., Kloft, W.J., DuBose, L.A. \& Kloft, E.S. (1977) Recontamination of food after feeding a $32 \mathrm{P}$ food source to biting Muscidae. Journal of Medical Entomology, 13, 567-571.

Caij, A.B. \& Tignon, M. (2014) Epidemiology and genetic characterization of equine infectious anaemia virus strains isolated in Belgium in 2010. Transboundary and Emerging Diseases, 61, 464-468.

Chippaux, J.-P., Bouchité, B., Demanou, M., Morlais, I. \& le Goff, G. (2000) Density and dispersal of the loaiasis vector Chrysops dimidiata in southern Cameroon. Medical and Veterinary Entomology, 14, 339-344.

Chlava, M., Lineborg, L. \& Moucha, J. (1972) The Horse Flies of Europe (Diptera, Tabanidae). Entomological society of Copenhagen, Copenhagen.

Cortes, H.C.E., Reis, Y., Waap, H. et al. (2006) Isolation of Besnoitia besnoiti from infected cattle in Portugal. Veterinary Parasitology, 141, 226-233.

Desquesnes, M., Dargantes, A., Lai, D.H., Lun, Z.R., Holzmuller, P. \& Jittapalapong, S. (2013) Trypanosoma evansi and Surra: a review and perspectives on transmission, epidemiology and control, impact, and zoonotic aspects. BioMed Research International, 2013, $1-20$.

Fernandez-Garcia, A., Alvarez-Garcia, G., Risco-Castillo, V. et al. (2010) Development and use of an indirect ELISA in an outbreak of bovine besnoitiosis in Spain. Veterinary Record, 166, 818-822.

Foil, L. (1983) A mark-recapture method for measuring effects of spatial separation of horses on tabanid (Diptera) movement between hosts. Journal of Medical Entomology, 20, 301-305.

Foil, L.D. (1989) Tabanids as vectors of disease agents. Parasitology Today, 5, 88-96.

Foil, L.D. \& Hogsette, J.A. (1994) Biology and control of tabanids, stable flies and horn flies. Revue Scientifique et Technique (International Office of Epizootics), 13, 1125-1158.

Foil, L.D. \& Issel, C.J. (1991) Transmission of retroviruses by arthropods. Annual Review of Entomology, 36, 355-381.

Foil, L.D., Adams, W.V., McManus, J.M. \& Issel, C.J. (1987) Bloodmeal residues on mouthparts of Tabanus fuscicostatus (Diptera: Tabanidae) and the potential for mechanical transmission of pathogens. Journal of Medical Entomology, 24, 613-616. 
Gutierrez, C., Desquesnes, M., Touratier, L. \& Büscher, P. (2010) Trypanosoma evansi: recent outbreaks in Europe. Veterinary Parasitology, 174, 26-29.

Hawkins, J.A., Adams, W.V., Cook, L., Wilson, B.H. \& Roth, E.E. (1973) Role of horse fly (Tabanus fuscicostatus Hine) and stable fly (Stomoxys calcitrans L.) in transmission of equine infectious anemia to ponies in Louisiana. American Journal of Veterinary Research, 34, $1583-1586$.

Hawkins, J.A., Adams, W.V. Jr., Wilson, B.H., Issel, C.J. \& Roth, E.E. (1976) Transmission of equine infectious anemia virus by Tabanus fuscicostatus. Journal of the American Veterinary Medical Association, 168, 63-64.

Heinze, G. \& Schemper, M. (2002) A solution to the problem of separation in logistic regression. Statistics in Medicine, 21, 2409-2419.

Herczeg, T., Száz, D., Blahó, M. et al. (2015) The effect of weather variables on the flight activity of horseflies (Diptera: Tabanidae) in the continental climate of Hungary. Parasitology Research, 114, 1087-1097.

Horvath, G., Blaho, M., Kriska, G. et al. (2010) An unexpected advantage of whiteness in horses: the most horsefly-proof horse has a depolarizing white coat. Proceedings of the Royal Society of London Series B: Biological Sciences, 277, 1643-1650.

Issel, C.J. \& Foil, L.D. (2015) Equine infectious anaemia and mechanical transmission: man and the wee beasties. Revue Scientifique et Technique (International Office of Epizootics), 34, 513-523.

Liénard, E., Salem, A., Grisez, C. et al. (2011) A longitudinal study of Besnoitia besnoiti infections and seasonal abundance of Stomoxys calcitrans in a dairy cattle farm of southwest France. Veterinary Parasitology, 177, 20-27.

Mullen, G.R. \& Durden, L.A. (2009) Medical and Veterinary Entomology. Elsevier, London.

Scoles, G.A., Broce, A.B., Lysyk, T.J. \& Palmer, G.H. (2005) Relative efficiency of biological transmission of Anaplasma marginale (Rickettsiales: Anaplasmataceae) by Dermacentor andersoni (Acari: Ixodidae) compared with mechanical transmission by Stomoxys calcitrans (Diptera: Muscidae). Journal of Medical Entomology, 42, 668-675.

Scoles, G.A., Miller, J.A. \& Foil, L.D. (2008) Comparison of the efficiency of biological transmission of Anaplasma marginale (Rickettsiales: Anaplasmataceae) by Dermacentor andersoni Stiles (Acari: Ixodidae) with mechanical transmission by the horse fly, Tabanus fuscicostatus Hine (Diptera: Muscidae). Journal of Medical Entomology, 45, 109-114.

Taylor, D.B., Moon, R.D., Campbell, J.B. et al. (2010) Dispersal of stable flies (Diptera: Muscidae) from larval development sites in a Nebraska landscape. Environmental Entomology, 39, 1101-1110.

Williams, D.L., Issel, C.J., Steelman, C.D., Adams, W.V. Jr. \& Benton, C.V. (1981) Studies with equine infectious anemia virus: transmission attempts by mosquitoes and survival of virus on vector mouthparts and hypodermic needles, and in mosquito tissue culture. American Journal of Veterinary Research, 42, 1469-1473.

Zumpt, F. (1973) The Stomoxyine Biting Flies of the World (Diptera: Muscidae). Wiley-VCH Verlag, Stuttgart.

Accepted 18 December 2017 